\title{
萠二酰亚胺：兼具高电子迁移率和双光子荧光性能的有机半导体
}

刘忠范

北京大学化学与分子工程学院, 北京 100871

\section{4,5,9,10-Pyrene Diimides: A Family of Aromatic Diimides Exhibiting High Electron Mobility and Two-Photon Excited Emission}

\section{LIU Zhongfan}

College of Chemistry and Molecular Engineering, Peking University, Beijing 100871, P. R. China.

Email: zfliu@pku.edu.cn

(a)

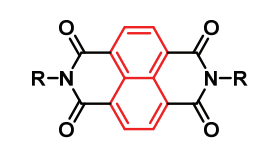

NDI
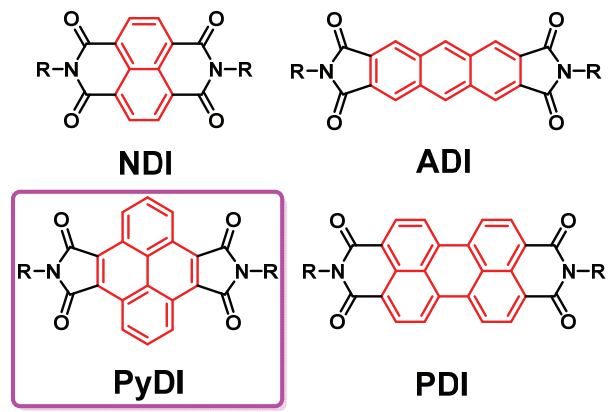

ADI (b) $\mathrm{e}$

(a) 新型有机半导体材料 PyDI 与传统芳香二酰亚胺类分子的结构对比; (b) 中间产物的能级调控
近年来, 伴随着有机电子学的蓬勃发展, 有机 半导体材料的研究逐渐成为了科研领域的热点之 一。与传统的无机半导体材料相比, 有机半导体材 料具备独特的优势, 比如分子结构易于调控、可溶 液处理和易于大规模制备 1,2 。有机半导体材料在新 一代电子产品, 诸如柔性器件、低功耗显示、电子 皮肤等领域有广泛的应用前景。

依据载流子类型划分, 有机半导体主要分为 $p$ 型(传输空穴)和 $n$-型(传输电子)材料。目前, $n$-型有 机半导体材料的发展远远落后于 $p$-型材料, 主要表 现在: 1) $n$-型材料的迁移率普遍偏低; 2) $n$-型材料 的数量和种类远少于 $p$-型; 3 ) 空气中稳定性不足 3 。 缺乏优秀的 $n$-型材料极大地限制了高性能有机光 电器件的开发及应用, 因此开发新型高性能的 $n$-型 有机半导体材料显得十分重要。
最近, 兰州大学化学化工学院张浩力教授课题 组报道了一类兼具高迁移率与良好发光性能的 $n$ 型有机半导体小分子, 4,5,9,10-萠二酰亚胺(PyDI)衍 生物。该工作提出了两种可行的合成路线, 在萠的 非活泼位点, 4、5、9、10 位进行亲电取代, 可以得 到多种 PyDI 类衍生物。他们通过调控烷基链, 并 控制从溶液中的结晶条件, 得到了高质量的晶体, 并进一步成功制备了单晶有机场效应晶体管器件。 基于 PyDI 的晶体管器件最高电子迁移率可以达到 $3.08 \mathrm{~cm}^{2} \cdot \mathrm{V}^{-1} \cdot \mathrm{s}^{-1}$, 足以謧美经典的菲二酰亚胺(PDI) 和菜二酰亚胺 $(\mathrm{NDI})^{4,5}$ 。同样重要的是 PyDI 以萠作 为基本结构, 继承了萠良好的发光特性, 显示出了 良好的双光子苂光性能。该工作同时发现, PyDI 分 子存在激基缔合物现象, 可以产生单体和激基缔合 物两种苂光发射, 可以被设计为基于单体-激基缔合 
物的荧光探针, 有广泛的应用前景。该研究与浙江 大学高分子科学与工程学系李寒莹教授课题组合 作完成。

该研究工作近期已在 Angewandte Chemie

International Edition 上在线发表 ${ }^{6}$ 。该工作不仅提 供了可行的合成路线, 合成了一系列 PyDI 分子及 其衍生物, 并且通过有效的性能调控, 展示了 PyDI 分子较高的迁移率。此外, 该分子兼具良好的发光 性能，有望应用在场效应晶体管、有机电致发光、 有机光伏器件和有机激光器等多种有机电子器件 中。

\section{References}

(1) Someya, T.; Bao, Z.; Malliaras, G. G. Nature 2016, 540, 379. doi: 10.1038 /nature21004

(2) Niazi, M. R.; Li, R.; Abdelsamie, M.; Zhao, K.; Anjum, D. H.; Payne, M. M.; Anthony, J.; Smilgies, D. M.; Amassian, A. Adv. Funct. Mater. 2016, 26, 2371. doi: 10.1002/adfm.201502428

(3) Wang, C.; Dong, H.; Hu, W.; Liu, Y.; Zhu, D. Chem. Rev. 2012, 112, 2208. doi: $10.1021 / \mathrm{cr} 100380 \mathrm{z}$

(4) He, T.; Stolte, M.; Burschka, C.; Hansen, N. H.; Musiol, T.; Kälblein, D.; Pflaum, J.; Tao, X.; Brill, J.; Würthner, F. Nat. Commun. 2015, 6, 5954. doi: $10.1038 /$ ncomms 6954

(5) Minder, N. A.; Ono, S.; Chen, Z.; Facchetti, A.; Morpurgo, A. F. Adv. Mater. 2012, 24, 503. doi: 10.1002/adma.201103960

(6) Wu, Z. H.; Huang, Z. T.; Guo, R. X.; Sun, C. L.; Chen, L. C.; Sun, B.; Shi, Z. F.; Shao, X.; Li, H.; Zhang, H. L. Angew. Chem. Int. Ed. 2017, doi: $10.1002 /$ anie. 201707529 